Check for updates

Cite this: RSC Adv., 2018, 8, 26488

\title{
Enhanced bioconversion of hydrogen and carbon dioxide to methane using a micro-nano sparger system: mass balance and energy consumption $\uparrow$
}

\author{
Ye Liu, ${ }^{a}$ Ying Wang, ${ }^{a}$ Xinlei Wen, ${ }^{a}$ Kazuya Shimizu, ${ }^{a}$ Zhongfang Lei, ${ }^{a}$ \\ Motoyoshi Kobayashi, ${ }^{a}$ Zhenya Zhang, (D) *a Ikuhiro Sumi, ${ }^{\text {b }}$ Yasuko Yao ${ }^{\text {b }}$ \\ and Yasuhiro Mogi ${ }^{\text {b }}$
}

Simultaneous $\mathrm{CO}_{2}$ removal with renewable biofuel production can be achieved by methanogens through conversion of $\mathrm{CO}_{2}$ and $\mathrm{H}_{2}$ into $\mathrm{CH}_{4}$. However, the low gas-liquid mass transfer $\left(k_{L} a\right)$ of $\mathrm{H}_{2}$ limits the commercial application of this bioconversion. This study tested and compared the gas-liquid mass transfer of $\mathrm{H}_{2}$ by using two stirred tank reactors (STRs) equipped with a micro-nano sparger (MNS) and common micro sparger (CMS), respectively. MNS was found to display superiority to CMS in methane production with the maximum methane evolution rate (MER) of $171.40 \mathrm{mmol} / \mathrm{L}_{R} / \mathrm{d}$ and $136.10 \mathrm{mmol} / \mathrm{L}_{R} /$ $\mathrm{d}$, along with a specific biomass growth rate of $0.15 \mathrm{~d}^{-1}$ and $0.09 \mathrm{~d}^{-1}$, respectively. Energy analysis indicated that the energy-productivity ratio for MNS was higher than that for CMS. This work suggests that MNS can be used as an applicable resolution to the limited $k_{\llcorner} a$ of $\mathrm{H}_{2}$ and thus enhance the bioconversion of $\mathrm{H}_{2}$ and $\mathrm{CO}_{2}$ to $\mathrm{CH}_{4}$.

Received 5th April 2018

Accepted 30th May 2018

DOI: $10.1039 / \mathrm{c} 8 \mathrm{ra02924e}$

rsc.li/rsc-advances this process realizes energy storage and conversion, as well as using the biological-based $\mathrm{CO}_{2}$ capture and sequestration technique. ${ }^{11,12}$ The calorific value can be improved by converting nonflammable $\mathrm{CO}_{2}$ to $\mathrm{CH}_{4}$ (with a calorific value of $55 \mathrm{~kJ} \mathrm{~kg}^{-1}$ ). Moreover, methanogens can produce not only methane but also valuable materials such as enzymes, amino acids, vitamins and so on. ${ }^{13}$

However, there are two key points in the bioconversion procedure. The first one is the source of the energy donor $\mathrm{H}_{2}$. In the previous study, $\mathrm{H}_{2}$ can be rapidly produced via water electrolysis, ${ }^{14}$ or obtained from biological process (biohydrogen).$^{15,16}$ While considering $\mathrm{H}_{2}$ is also a co-product in the steel sector, it is a promising alternative to utilize the waste $\mathrm{H}_{2}$ to realize the bioconversion. Meanwhile, $\mathrm{CH}_{4}$ as the product of the bioconversion is also regarded as an energy carrier for electricity storage, which is more easily transported or stored than $\mathrm{H}_{2} \cdot{ }^{17}$

The second point, also the big obstacle to the successful development of the technology for scaling up is the poor gasliquid mass transfer rate $\left(k_{\mathrm{L}} a\right)$ of low soluble $\mathrm{H}_{2}$ gas. ${ }^{18-20}$ When gas is sparged into the liquid, the $k_{\mathrm{L}} a$ principally depends on the size and number of bubbles present, ${ }^{21}$ which are affected by many factors such as agitation speed, ${ }^{22}$ gas or liquid flow rate, ${ }^{23}$ reactor geometry ${ }^{11,23}$ and the nature of the liquid. ${ }^{24}$ Various methods were employed to improve the $k_{\mathrm{L}} a$ value of $\mathrm{H}_{2}$. Kougias et $a .^{25}$ demonstrated successful ex situ biogas upgrading in different systems by the action of hydrogenotrophic methanogens. Compared with the continuous stirred tank reactor (CSTR) and bubble column reactor, the two connected up-flow 
reactor gained the highest efficiency of biogas upgrading with the $\mathrm{CH}_{4}$ content of $98 \%$. Bassani et al. ${ }^{19}$ constructed a granular UASB coupled with a separate chamber for $\mathrm{H}_{2}$ injection. The $k_{\mathrm{L}} a$ value of $\mathrm{H}_{2}$ was improved by different packing materials (rashing rings and alumina ceramic sponge), which lead to a maximum increase of $24 \%$ in $\mathrm{CH}_{4}$ content. While the $k_{\mathrm{L}} a$ value of hydrogen was not mentioned. Diaz et al. ${ }^{20}$ evaluated the potential of a pilot hollow-fiber membrane bioreactor for the conversion of $\mathrm{H}_{2}$ and $\mathrm{CO}_{2}$ to $\mathrm{CH}_{4}$. The system transformed $95 \%$ of $\mathrm{H}_{2}$ and $\mathrm{CO}_{2}$ fed at a maximum loading rate of $40.2 \mathrm{~m}_{\mathrm{H}_{2}}{ }^{3} / \mathrm{m}_{\mathrm{R}}{ }^{3} \mathrm{~d}$ and produced $0.22 \mathrm{~m}^{3}$ of $\mathrm{CH}_{4}$ per $\mathrm{m}^{3}$ of $\mathrm{H}_{2}$ fed at thermophilic conditions. $k_{\mathrm{L}} a-\mathrm{H}_{2}$ of $430 \mathrm{~h}^{-1}$ were reached in the bioreactor by sparging gas through the membrane module. Luo and Angelidaki ${ }^{23}$ used the CSTR equipped with a column diffuser (pore diameters $0.5-1.0 \mathrm{~mm}$ ) or ceramic diffuser $(14-40 \mu \mathrm{m})$ to realize in situ biogas upgrading by co-digestion of manure and whey with the addition of $\mathrm{H}_{2}$. The decrease in pore size of diffusers lead to an increase in $k_{\mathrm{L}} a$ value from $6.60 \mathrm{~h}^{-1}$ to $16.05 \mathrm{~h}^{-1}$. While much higher $k_{\mathrm{L}} a$ values of $\mathrm{H}_{2}\left(105-776 \mathrm{~h}^{-1}\right)$ were reached by up-flow reactors in the research of Bassani et al. ${ }^{26}$ Converse to the result of Luo and Angelidaki, ${ }^{23}$ the smaller pore size lead to the lower $k_{\mathrm{L}} a$ value, which was illustrated that the more efficient gas bubble break was caused by the larger pore size devices. Although various enhancement measures have improved the $k_{\mathrm{L}} a$ of $\mathrm{H}_{2}$ and $\mathrm{CH}_{4}$ production significantly, the energy consumption and practical viability of them should be carefully evaluated for their applications in large scale fermentation systems. What's more, not only the $\mathrm{CH}_{4}$ yield and $k_{\mathrm{L}} a-\mathrm{H}_{2}$, but also the intermediates variation and biomass growth should be taken into deep consideration, to understand the evolution of carbon and hydrogen.

Recently, a special attention has been paid to the application of micro-nano bubbles (MNBs) technology in many fields, including medicine science,${ }^{27}$ food science,${ }^{28}$ aquaculture,${ }^{29}$ and water remediation. ${ }^{30}$ Several special characteristics of MNBs, such as high specific area (surface area per volume) and high stagnation in liquid phase, increase the gas dissolution. Moreover, it has been reported that the collapse of micro-bubbles, due to the high density of ions in gas-liquid interface just before the collapse, will lead to free radical generation, which might be favorable for microbial metabolism and further stimulate the bioactivity. ${ }^{31}$ Up to now, however, little information can be found on the combination of MNBs with methanogenesis. Except the methane production performance and mass transfer of $\mathrm{H}_{2}$, it is worthy to explore the interaction of bubbles and microbes.

In this study, MNBs were applied for the bioconversion of $\mathrm{H}_{2}$ and $\mathrm{CO}_{2}$ to $\mathrm{CH}_{4}$, aiming at supplying a sufficient interaction of gaseous substrates and methanogens. The effect of MNBs on methanogens was achieved by operating two bioreactors equipped with micro-nano sparger (MNS) and common micro sparger (CMS), respectively. The gas-liquid mass transfer of hydrogen was also determined in this study. Bubble size distribution of the two spargers were analyzed to calculate the specific surface area. By analyzing the variations of reactants and products in the two bioreactors and conducting the mass balance analysis, deeply understand the evolution procedure of carbon and hydrogen. Also, the energy consumption analysis was conducted to figure out the commercialization potential of MNS.

\section{Materials and methods}

\section{Experimental apparatus and operation conditions}

This study was carried out in two identical stirred tank reactors (STRs) equipped with a micro-nano sparger (MNS) (Foamest Column 16-60, Nac sales corporation, Japan) and a common micro sparger (CMS) (HA003, Haohai, China), respectively. The two reactors have a same total volume of $1.1 \mathrm{~L}$ (headspace : liquid $=6: 5, \mathrm{v} / \mathrm{v})$. The $\mathrm{H}_{2}$ and $\mathrm{CO}_{2}$ gas mixture $(80 / 20, \mathrm{v} /$ v) was transferred from the head space of the reactor to the liquid phase by a diaphragm pump (GS-6EA, E.M.P.-Japan Ltd,

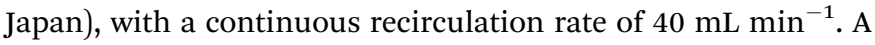
gas holder connected to the head space of the reactor was used to allow fermentation to proceed without creating vacuum and maintain a positive and constant pressure inside the reactor during the fermentation. A magnetic stirrer was employed for both reactors to maintain mixing (500 rpm) and temperature maintenance $\left(37 \pm 2{ }^{\circ} \mathrm{C}\right)$. All the tube connections, stoppers, and seals were made of butyl rubber and glass. The diagram of the experimental setup in this study is illustrated in Fig. 1.

\section{Inoculum and medium}

The acclimated inocula, collected from the pond sediment (Matsumi Ike, Tsukuba campus) which has been well adapted to the $\mathrm{H}_{2} / \mathrm{CO}_{2}$ gas mixture $(80 / 20, \mathrm{v} / \mathrm{v})$ for 4 months' methane production, were introduced at a ratio of $1: 4(\mathrm{v} / \mathrm{v})$ into the medium. The compositions of medium were the same as a previous study. ${ }^{32}$

\section{Analytical methods}

The contents of $\mathrm{H}_{2}, \mathrm{CO}_{2}$, and $\mathrm{CH}_{4}$ in the gas phase were analyzed by gas chromatograph (Shimadzu GC-8A, Japan) equipped with a thermal conductivity detector connected to

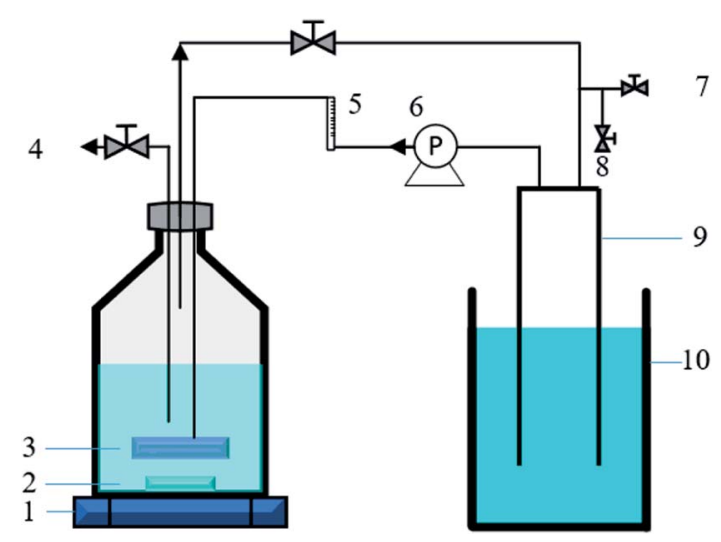

Fig. 1 Schematic diagram of the batch fermentation system. (1) Magnetic stirrer, (2) rotor, (3) micro-nano sparger (or common micro sparger), (4) liquid sample port, (5) flow meter, (6) gas recirculation pump, (7) gas input port, (8) gas sample port, (9) gas holder, (10) saturated sodium bicarbonate solution. 
a chromatopac data analyzer (Shimadzu C-R4A, Japan). A stainless steel column packed with Porapak-Q was used for the analysis, with the temperatures of both detector and injector at $60{ }^{\circ} \mathrm{C}$ and of the column at $80{ }^{\circ} \mathrm{C}$, respectively. $\mathrm{N}_{2}$ was used as the carrier gas at an inlet pressure of $199 \mathrm{kPa}$ and an outlet pressure of $150 \mathrm{kPa}$, respectively. The gas samples were taken at an interval of $24 \mathrm{~h}$.

Total solid (TS), volatile solid (VS), and biomass concentration were analyzed according to the standard methods. ${ }^{33}$ Volatile fatty acids (VFAs) were analyzed by gas chromatography (GCFID, Shimadzu C-R8A, Japan). Soluble carbon was analyzed by a TOC analyzer (Shimadzu TOC-V $\mathrm{V}_{\mathrm{CSN}}$, Japan). The liquid samples were collected every three days, which were used for VFAs analysis after filtration through $0.22 \mu \mathrm{m}$ filters. $3 \%$ phosphoric acid solution was added to the filtrate to acidify samples at a volume ratio of $1: 9$ for the analysis of volatile fatty acids (VFAs). Gas chromatograph (GC-8A, Shimadzu) equipped with Unisole F-200 30/60 column and flame ionization detector (FID) was used for quantification of VFAs, including acetic acid (HAc), propionic acid (HPr), iso-butyric acid (iso-HBu), $n$-butyric acid $(n-\mathrm{HBu})$, iso-valeric acid (iso-HVa) and $n$-valeric acid ( $n$ $\mathrm{HVa}){ }^{34}$

The bubble size distribution from the two sparger systems was analyzed by Nano Sight (nano scale bubbles) and a highspeed camera (micro scale bubbles) with distilled water as the media. The mean bubble size was utilized for the calculation of specific surface area.

The mass transfer coefficient $\left(k_{\mathrm{L}} a\right)$ of $\mathrm{H}_{2}$ was determined before inoculation. $\mathrm{H}_{2}$ was supplied to the reactors continuously. $\mathrm{H}_{2}$ gas samples were collected from a three-way gas sampling port at an interval of $5 \mathrm{~min}$. The first gas sample was collected at 2 min after the introduction of $\mathrm{H}_{2}$ gas into the reactor. Once being collected, the gas sample was injected into a $20 \mathrm{~mL}$ sealed vial which contained some water at a same gas phase to liquid phase ratio as the reactor. Then the gas and the liquid was well mixed using a vortex mixer for $1 \mathrm{~min}$ and allowed $1 \mathrm{~h}$ to equilibrate the gas and the liquid phases. A gas sample from the head space was then taken and analyzed for gas composition in the gaseous phase using GC-TCD (Shimadzu GC-8A, Japan). The gas content in the head space was then converted to the aqueous phase concentration according to Henry's law (eqn (1)).

$$
K_{\mathrm{H}}=\frac{P}{X}
$$

where, $K_{\mathrm{H}}$ is the Henry's law constant (atm), $P$ is the partial pressure of gas above the aqueous phase (atm) and $X$ is the mole fraction of gas in the solution (unitless). The Henry's law constant used for $\mathrm{H}_{2}$ in this analysis was $7.52 \times 10^{4}$ atm (at $35{ }^{\circ} \mathrm{C}$ and $\left.1 \mathrm{~atm}\right)$.

SEM images were taken by Field Emission Scanning Electron Microscope (FE-SEM, S-4800; Hitachi Hitec Corp, Japan) using the samples during the stable operation of the two reactors (on day 38). The samples were diluted by ten times and dried for one night in the oven $\left(40 \pm 1^{\circ} \mathrm{C}\right)$ before being used for analysis.

\section{Calculation}

Determination of $\boldsymbol{k}_{\mathrm{L}} \boldsymbol{a}$ of hydrogen. Assuming that the concentration in the liquid phase at the gas-liquid interface is in equilibrium with the gas concentration in the gaseous phase, the volumetric mass transfer coefficient $\left(k_{\mathrm{L}} a\right)$ in the absence of microorganisms was determined using the following equation (eqn (2)).

$$
\frac{\mathrm{d} c}{\mathrm{~d} t}=k_{\mathrm{L}} a\left(C_{\mathrm{i}}-C\right)
$$

where, $C$ is the gas concentration in the liquid phase $\left(\mathrm{mg} \mathrm{L}^{-1}\right)$ at any given time $t(\mathrm{~min})$, and $C_{\mathrm{i}}$ is the saturated gas concentration $\left(\mathrm{mg} \mathrm{L}^{-1}\right)$. eqn (2) can be further simplified to eqn (3),

$$
\ln \left(\frac{C_{\mathrm{i}}-C_{0}}{C_{\mathrm{i}}-C}\right)=\left(k_{\mathrm{L}} a\right) t
$$

where, $C_{0}$ is the initial gas concentration in the liquid phase $\left(\mathrm{mg} \mathrm{L}^{-1}\right)$.

Hydrogen conversion efficiency. Hydrogen was provided as the sole electron donor for the batch experiments. As the total mass of $\mathrm{H}_{2}$ supplied into the systems $\left(m_{\mathrm{G}_{\mathrm{H}_{2}, \text { in }}}\right)$ is the sum of the mass utilized by the microbes and the mass left (effluent) in the system, the $\mathrm{H}_{2}$ conversion efficiency (\%) was calculated according to eqn (4),

$$
\eta_{\mathrm{H}_{2}}=100 \times\left(m_{\mathrm{G}_{\mathrm{H}_{2}, \text { in }}}-m_{\mathrm{G}_{\mathrm{H}_{2}, \text { eff }}}\right) / m_{\mathrm{G}_{\mathrm{H}_{2}} \text {, in }}
$$

where $m_{\mathrm{G}_{\mathrm{H}_{2}} \text {, in }}$ is the mass flow rate of $\mathrm{H}_{2}$ fed into the reactor per day and $m_{\mathrm{G}_{\mathrm{H}_{2} \text {,eff }}}$ is the mass flow rate of $\mathrm{H}_{2}$ in the effluent gas. The utilized $\mathrm{H}_{2}\left(m_{\mathrm{H}_{2}, \text { utl }}\right)$ was the difference between $m_{\mathrm{G}_{\mathrm{H}_{2} \text {, in }}}$ and $m_{\mathrm{G}_{\mathrm{H}_{2}, \text { eff }}}$, as shown in eqn (5):

$$
m_{\mathrm{H}_{2}, \mathrm{utl}}=m_{\mathrm{G}_{\mathrm{H}_{2}, \text { in }}}-m_{\mathrm{G}_{\mathrm{H}_{2}, \text { eff }}}
$$

$m_{\mathrm{H}_{2} \text {,utl }}$ can be classified into two parts, $\mathrm{H}_{2}$ employed for microorganisms growth (anabolism) and consumed to produce energy (catabolism). Since the $\mathrm{H}_{2}$ as an energy source can be transferred to VFAs as the intermediates and $\mathrm{CH}_{4}$ as the final product, the utilized $\mathrm{H}_{2}$ can be quantified according to eqn (6).

$$
m_{\mathrm{H}_{2}, \mathrm{utl}}=m_{\mathrm{CH}_{4}, \mathrm{H}_{2}}+m_{\mathrm{VFAs}, \mathrm{H}_{2}}+m_{\text {growth }, \mathrm{H}_{2}}
$$

where $m_{\mathrm{CH}_{4}, \mathrm{H}_{2}}$ is the mass of $\mathrm{CH}_{4}$ as equivalent $\mathrm{H}_{2}, m_{\mathrm{VFAs}, \mathrm{H}_{2}}$ is that of $\mathrm{H}_{2}$ transferred into VFAs, and $m_{\text {growth, } \mathrm{H}_{2}}$ is that of $\mathrm{H}_{2}$ employed for microbial growth.

Carbon balance analysis. The carbon was supplied in three phases in this study: $\mathrm{CO}_{2}$ (gas phase), $\mathrm{Na}_{2} \mathrm{CO}_{3}$ (liquid phase), and inoculum or biomass (solid phase), which can be expressed as follows:

$$
C_{\mathrm{Total}, \text { in }}=C_{\mathrm{in}, \mathrm{G}, \mathrm{CO}_{2}}+C_{\mathrm{L}, \text { medium }}+C_{\mathrm{S}, \text { biomass }}
$$

After the reaction, $\mathrm{CO}_{2}$ can be transferred into $\mathrm{CH}_{4}$, VFAs, and utilized for microbial growth, and other metabolites. Finally, the unreacted $\mathrm{CO}_{2}$ was left in the system.

$$
C_{\mathrm{Total}, \text { in }}=C_{\mathrm{G}, \mathrm{CH}_{4}}+C_{\mathrm{G}, \mathrm{CO}_{2}, \text { eff }}+C_{\mathrm{L}, \mathrm{VFAs}}+C_{\mathrm{L}, \text { other }}+C_{\mathrm{S}, \text { biomass }}
$$


Estimation of Monod kinetic parameters for the batch experiments. In order to estimate the maximum specific growth rate $\left(\mu_{\text {max }}\right)$, the nutrients were supplied sufficiently to create the condition of nutrients concentration $(C) \gg K_{\mathrm{s}}\left(\right.$ i.e. $C /\left(K_{\mathrm{s}}+C\right) \approx$ 1). During the exponential growth phase, the Monod equation can be simplified to eqn (9).

$$
\left(\frac{\mathrm{d} X}{\mathrm{~d} t}\right)_{\text {growth }}=\mu_{\max } X
$$

where $\mu_{\max }$ is the maximum specific growth rate $\left(\mathrm{d}^{-1}\right)$. Then, $\mu_{\text {max }}$ can be obtained by eqn (10):

$$
\mu_{\max }=\frac{1}{t} \ln \frac{X_{t}}{X_{0}}
$$

where $X_{0}$ is the initial biomass concentration (g-biomass per L) and $X_{t}$ is the biomass concentration at time $t$ during exponential growth with no limitation of nutrients (g-biomass per L).

Energy consumption analysis. The electricity consumed by the systems was estimated by monitoring the energy consumption of the related devices. The energy input was the sum of electricity consumed by pumps and stirrers, as shown in eqn (11):

$$
E_{\text {consumed }}=E_{\text {pump }}+E_{\text {stirrer }}
$$

where $E_{\text {consumed }}, E_{\text {pump }}$ and $E_{\text {stirrer }}$ are the total energy consumed by the system, the energy consumed by pump and stirrer, respectively.

The energy-product ratio $(R)$ was calculated by eqn (12).

$$
R=\frac{Y_{\mathrm{CH}_{4} \text {,total }}}{E_{\text {consumed }}}
$$

where $R$ is the energy-product ratio $\left(\mathrm{L} \mathrm{kW}^{-1}\right), Y_{\mathrm{CH}_{4} \text {,total }}$ is the accumulated methane production during the whole experimental period $(\mathrm{L})$. The energy consumption is mainly attributable to the heat loss during the operation with a small amount utilized by the growth of microbes.

Statistic analysis. All the data were expressed as mean value \pm standard deviation in this study. The significance of difference in the quantitative variables $\left(e . g\right.$. $\mathrm{CH}_{4}$ content in the output gas) between the two reactor systems was analyzed by one-way analysis of variance (ANOVA) using Origin 9.0 (Originlab, USA), and significance was assumed at $p<0.05$. Moreover, regarding the microbial community, statistical analysis was carried out as previously described by Tsapekos et al. ${ }^{35}$ to identify the significant abundance difference in microorganisms among the samples.

\section{Results and discussion}

\section{Bioconversion performance}

Methane production. To compare the effect of MNS and CMS on $\mathrm{CH}_{4}$ production, the MNS reactor (MNSR) and CMS reactor (CMSR) systems were established to produce $\mathrm{CH}_{4}$ from $\mathrm{H}_{2}$ and $\mathrm{CO}_{2}$. A start-up period was noticed in both reactors with a gradually increased methane production rate (Fig. 2), due to the adaption of methanogens to the new conditions. While the

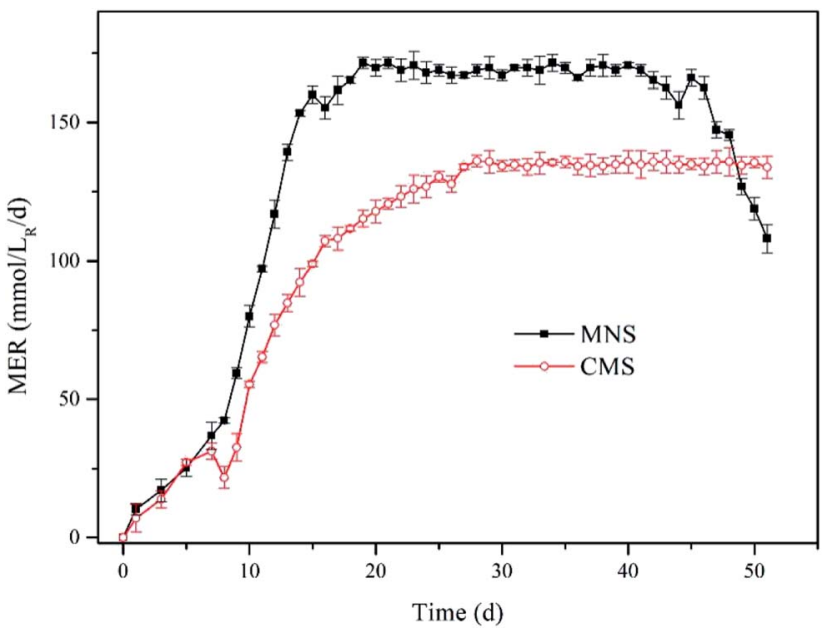

Fig. 2 Methane evolution rate (MER) for the two reactors. Solid squares denote MNSR and open circles denote CMSR.

methane production trended to be stable from day 14 to day 45 with the maximum methane evaluation rate (MER) of 171.40 $\mathrm{mmol} / \mathrm{L}_{\mathrm{R}} / \mathrm{d}$ in the MNSR. Similarly, the stable phase in the CMSR was detected from day 27 to day 50, achieving the maximum MER of $136.10 \mathrm{mmol} / \mathrm{L}_{\mathrm{R}} / \mathrm{d}$. The enhancement of methane yield in the MNSR is significant with the $p$ value lower than 0.05. The delayed achievement on the maximum MER in the CMSR was most probably attributed to its lower biomass growth rate. At the very beginning, both the aqueous substrates and the gaseous substrates were sufficient for the microbes, so that the microbial growth exhibited a rapid increase which agrees with the increase in methane production, the major product in this kind of systems. However, when the biomass increased to some extent, the dissolved hydrogen concentration (DHC) became the limiting factor for the microbes, leading to the maximum methane production maintained at a stable period. From day 46 to day 51, the MER of MNSR began to decrease gradually, as a result of the exhaustion of some nutrients in the medium. The results from this study indicate that MNSR can produce more $\mathrm{CH}_{4}$ than CMSR.

The finding of this work is to some extent similar to that of Weimer \& Zeikus $^{36}$ who used Methanosarcina barkeri MS as the inoculum, achieving the MER of $5.539 \mathrm{mmol} \mathrm{L}^{-1} \mathrm{~h}$ in a $2 \mathrm{~L}$ reactor under fed-batch mode conditions. Their result is comparable to the MER of CMSR, while lower than that of MNSR. The current work is also comparable to Roennow \& Gunnarsson $^{37}$ who carried out the fed-batch experiments in a $1 \mathrm{~L}$ reactor. For recent studies, the methane production has been improved greatly by various methods. Lee et al. ${ }^{38}$ converted $\mathrm{H}_{2}$ and $\mathrm{CO}_{2}$ to methane by a fixed bed reactor with the mixed culture, and got the conclusion that the maximum methane production of $143.97 \mathrm{~mol} \mathrm{~L}^{-1} \mathrm{~d}^{-1}$, which is much higher than this study. The low methane yield in this study was closely related to the low feeding rate of gaseous substrates.

$\mathbf{H}_{2}$ utilization efficiency. In order to confirm that the enhancement on $\mathrm{CH}_{4}$ production by MNSR was brought about by improvement of $k_{\mathrm{L}} a$ using MNBs, $\mathrm{H}_{2}$ balance analysis was used to investigate whether the bioconversion efficiency of $\mathrm{H}_{2}$ 


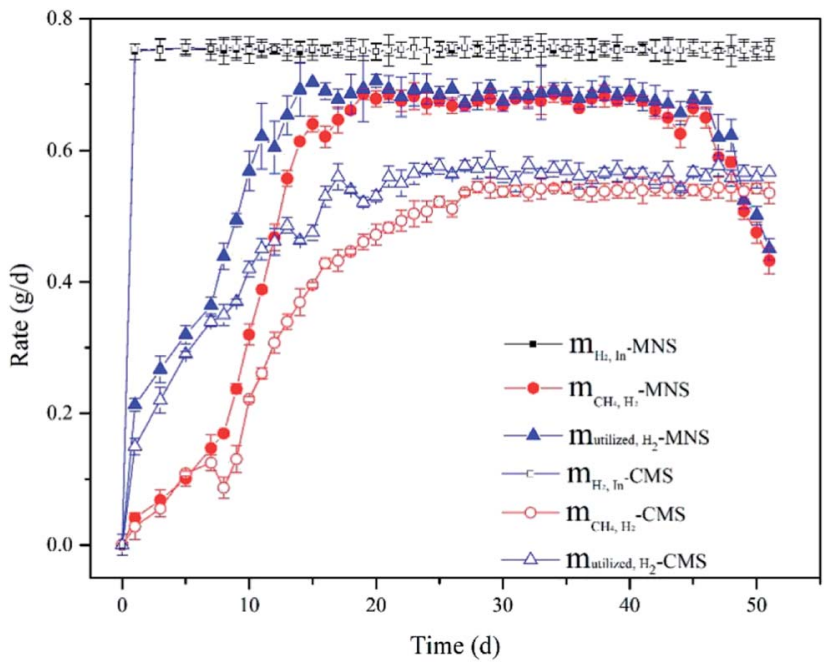

Fig. $3 \mathrm{H}_{2}$ balance analysis for the two reactor systems.

was stimulated by the MNBs or not. The utilized $\mathrm{H}_{2}$ concentration was calculated by eqn (5). As shown in Fig. $3, \mathrm{H}_{2}$ was not exhausted in both MNSR and CMSR, due to the decreased dissolved $\mathrm{H}_{2}$ concentration along with operation time, resulting in weakened driving force for gas-liquid mass transfer. As the same trend with $\mathrm{CH}_{4}$ production, $\mathrm{H}_{2}$ consumption increased gradually, and then became stable for some period. The maximum $\mathrm{H}_{2}$ utilization in the MNSR was detected on day 20 with the maximum $\eta_{\mathrm{H}_{2}}$ of $95 \%$. In comparison to MNSR, $m_{\mathrm{H}_{2} \text {,utl }}$ in the CSR was lower, correspondingly yielding to a lower maximum $\eta_{\mathrm{H}_{2}}$ of $80 \%$ (day 25). Albeit the methane yield in this study was low, the $\mathrm{H}_{2}$ utilization efficiency of MNS is high and comparable with other studies, ${ }^{20,38}$ indicating the smaller bubbles can be utilized effectively by the methanogens. This observation implies that MNS can transfer more $\mathrm{H}_{2}$ from gas phase into liquid phase during the same operation duration compared with CMS. An ideal condition for the bioconversion is that $\mathrm{H}_{2}$ could be transferred at a high rate without any accumulation. The maximum dissolved hydrogen concentration in the water is about $1.6 \mathrm{mg} \mathrm{L}^{-1}$ at normal pressure. ${ }^{39}$ While the utilized hydrogen concentration in the two reactors is much higher than $1.6 \mathrm{mg} \mathrm{L}^{-1}$, illustrating that $\mathrm{H}_{2}$ was consumed by the microbes. The $\mathrm{H}_{2}$ converted to $\mathrm{CH}_{4}\left(m_{\mathrm{CH}_{4}, \mathrm{H}_{2}}\right)$ was lower than the utilized $\mathrm{H}_{2}$ concentration $\left(m_{\mathrm{H}_{2}, \mathrm{ut}}\right)$, indicating that there could be a prior in biomass growth than $\mathrm{CH}_{4}$ production. From day 20 on, the $m_{\mathrm{CH}_{4}, \mathrm{H}_{2}}$ in the MNSR contributed over $95 \%$ to the total utilization of $\mathrm{H}_{2}$, and maintained at this high proportion for about 20 days. The $\mathrm{CH}_{4}$ production in both reactors did not show a continuous increase, demonstrating the lack of dissolved hydrogen for methanogens. Specifically, the contribution of $m_{\mathrm{CH}_{4}, \mathrm{H}_{2}}$ in the CMSR to $m_{\mathrm{H}_{2} \text {,utl }}$ was slightly lower (about $90 \%$ ), indicating $\mathrm{H}_{2}$ was also engaged in VFAs production and biomass growth.

\section{Biomass enrichment}

To determine the effect of MNBs on biomass growth, biomass concentration was quantified in time course (Fig. 4). The superiority of the MNSR was not obvious till day 5 . After day 5

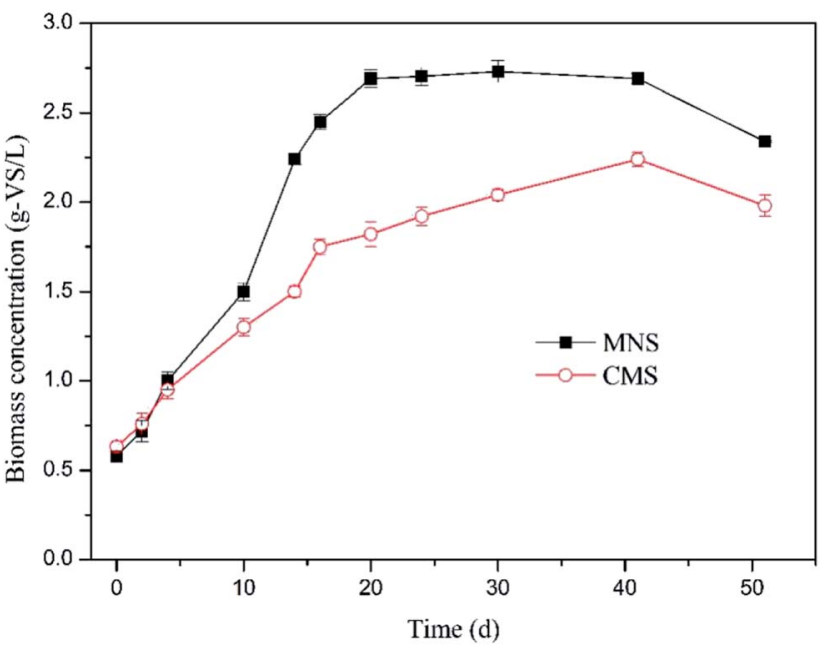

Fig. 4 Variation in biomass concentration in the two reactors. Solid squares denote MNSR and open circles denote CMSR.

the MNSR experienced a rapid increase in biomass and earned a higher maximum specific growth rate of $0.15 \mathrm{~d}^{-1}$ in comparison to $0.09 \mathrm{~d}^{-1}$ in the CMSR. The methanogens in the two reactors were shown in Fig. S1. $\dagger$ Results suggest that methanogens use more dissolved $\mathrm{H}_{2}$ in MNSR due to its higher $k_{\mathrm{L}} a$. However, the biomass concentration showed a stable trend following the rapid growth period, demonstrating that the dissolved $\mathrm{H}_{2}$ concentration was still the limiting factor which dominates $\mathrm{H}_{2}$ utilization for catabolism reactions $\left(\mathrm{CH}_{4}\right.$ production). The inocula used in this study was the acclimated anaerobic sludge, a mixed culture. Compared to the pure culture, generally the mixed culture is more advantageous regarding availability and cost, if not thinking about the relatively lower conversion rate due to the competitive communities. Moreover, the MNSR can be applied in large-scale tests according to the results from the acclimated anaerobic sludge.

\section{Variation in volatile fatty acids (VFAs)}

Anaerobic conversion of $\mathrm{CO}_{2}$ can support a variety of microorganisms from different trophic groups within a microbial community. Therefore, the pathways involved in $\mathrm{CH}_{4}$ production from $\mathrm{CO}_{2}$ become more complex when taking the mixed anaerobic consortium into consideration. For a mixed methanogenic culture, i.e. the acclimated anaerobic sludge used in this study, it is essential to consider all possible reactions that are involved in the conversion of $\mathrm{CO}_{2}$ to $\mathrm{CH}_{4}$. The possible pathways indicate that hydrogenotrophic methanogens can directly convert $\mathrm{H}_{2}$ and $\mathrm{CO}_{2}$ to $\mathrm{CH}_{4}$ through the pathway (a) (Fig. S2 $\dagger$ ). On the other hand, homoacetogenic bacteria can participate in the conversion of the $\mathrm{H}_{2}$ and $\mathrm{CO}_{2}$ to acetate, a thermodynamically favorable reaction (pathway (b)). Then the acetoclastic methanogenesis will occur according to the pathway (c). Conversely, syntrophic acetate-oxidizing (SAO) bacteria can convert acetate to $\mathrm{H}_{2}$ and $\mathrm{CO}_{2}$ (pathway (d)) when acetoclastic methanogenesis is deficient. ${ }^{40}$ The SAO reaction becomes thermodynamically favorable at low $\mathrm{H}_{2}$ partial pressure $\left(<10^{-4}\right.$ atm at $\left.35^{\circ} \mathrm{C}\right) 4^{41,42}$ 


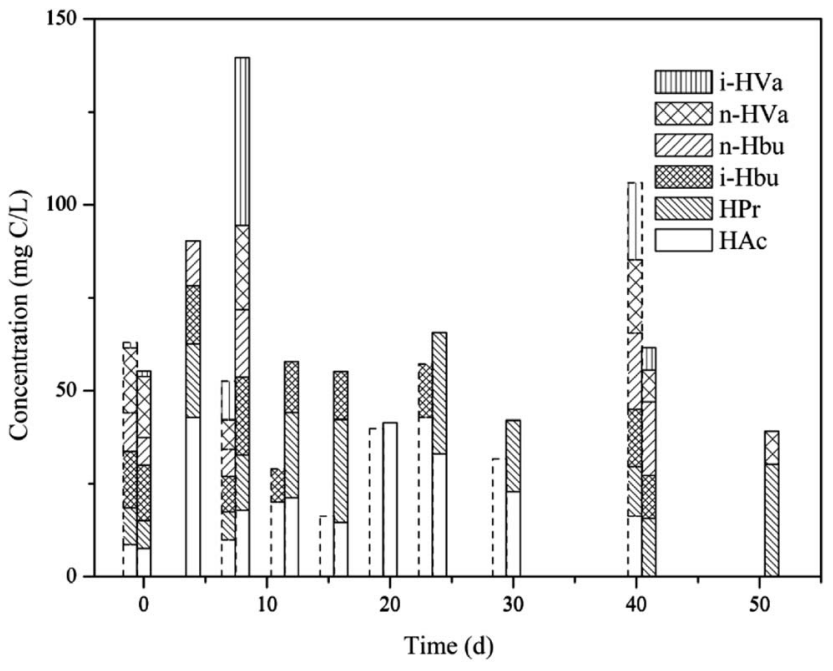

Fig. 5 VFAs variations in the two reactors (dashed line: MNSR; solid line: CMSR).

As shown in Fig. 5, VFAs accumulation was not detectable in the MNSR during the first week. Then VFAs concentration increased with the increase in $\mathrm{CH}_{4}$ production. However, at the end of the experiments VFAs was not detectable in the MNSR, indicating that VFAs in this reactor experienced a production followed by consumption progress. It has been pointed out that a high dissolved $\mathrm{H}_{2}$ concentration inhibits propionate and butyrate conversion to acetate or $\mathrm{H}_{2}$ and $\mathrm{CO}_{2}$ during anaerobic digestion, yielding lower conversion rate or the whole process breakdown. ${ }^{20}$ Thus, a higher acetic acid concentration in the MNSR can be used for more $\mathrm{CH}_{4}$ production when compared to the CMSR, possibly contributed by the higher dissolved $\mathrm{H}_{2}$ concentration in the reactor.

From the whole process, the concentration of total VFAs in the MNSR was lower than that in the CMSR, indicating more substrates were converted into $\mathrm{CH}_{4}$. Meanwhile in the CMSR, VFAs accumulation was detected at the beginning of experiment. From day 12, the total VFAs concentration decreased while maintained at a relatively stable level, reflecting that VFAs consumption in the CMSR was not so efficient.

\section{Carbon mass balance analysis}

To evaluate carbon conversion efficiency in the reactors, carbon elements in the liquid, solid and gaseous phases were quantified as illustrated in Fig. 6 . The $\mathrm{C}$ content in biomass was estimated according to a theoretical formula $\left(\mathrm{C}_{60} \mathrm{H}_{87} \mathrm{~N}_{12} \mathrm{O}_{23} \mathrm{P}\right)$ for microbes. In addition, the calculation of $C_{\mathrm{L}, \mathrm{TVFAs}}$ was based on the individual VFA. During the whole experiments, except for the initial carbon in the biomass and medium, the carbon input is only from $\mathrm{CO}_{2}$ in the gas phase. The carbon balance was analyzed according to eqn (8). Being consistent with the results from above two sections, a relatively more carbon conversion into the solid phase ( $\left.C_{\mathrm{S} \text {,Biomass }}\right)$ was achieved in the MNSR in comparison to the CMSR. And the final biomass yield in the MNSR was $2.34 \mathrm{~g}$-biomass per $\mathrm{L}$, which was $1.98 \mathrm{~g}$-biomass per $\mathrm{L}$ in the CMSR. Anyhow, the liquid phase carbon percentage gradually was found to decrease to a low level in both reactors, which might be utilized as a source for biomass growth. Considering the gaseous phase carbon fractions, $C_{\mathrm{G}, \mathrm{CH} 4}$ in the two reactors showed a remarkable difference. Still, a considerable part of $\mathrm{CO}_{2}\left(C_{\mathrm{G}, \mathrm{CO}_{2}, \text { Rest }}\right)$ was remained in both systems. Seen from the whole conversion process, the input $\mathrm{CO}_{2}$ tended to be employed for microbial growth first, and then the $C_{\mathrm{G}, \mathrm{CH}_{4}}$ increased with the increase in biomass growth.

\section{Energy consumption}

The economic and practical feasibility of this enhancement approach should be evaluated for its applications in large scale fermentation systems. MNS clearly has a significant stimulation potential for hydrogenotrophic methanogenesis. Enrichment of methanogens in the MNSR provides a greater $\mathrm{H}_{2}$-bioconversion potential than in the CMSR, suggesting that the gas-liquid mass transfer limitation is minimized. However, the advantage could be mitigated by high energy consumption. In this context, energy consumption analysis is essential for both the MNSR and CMSR. Table 1 summarizes the results relating to the energy consumptions by the MNSR and CMSR according to eqn (11) and (12).

As shown in Table 1 , both the work of pump $\left(E_{\text {pump }}\right)$ and stirrer $\left(E_{\text {stirrer }}\right)$ in the MNSR were higher than those in the CMSR, leading to the higher energy consumption in the MNSR system. However, when evaluating the technology, the product value ( $\mathrm{CH}_{4}$ in this work) also should be taken into account. In this work, the energy-product ratio $(R)$ was employed to represent the potential for practical application. As for the MNSR, although a higher $\mathrm{CH}_{4}$ yield is corresponding to a higher energy consumption, its $R$ value is still higher than the that for the CMSR, demonstrating its great potential for scaling-up application. In fact, continuous-type reactors dominate the industrial scale fermentation systems, and the methane yield can also be improved by increasing the gas recirculation rate. As proposed by Szuhaj et al., ${ }^{13}$ the energy for $\mathrm{H}_{2}$ production could be supplied by the renewable resources such as the wind or solar energy. In this case, the application of MNSR for bioconversion of $\mathrm{H}_{2}$ and $\mathrm{CO}_{2}$ is more meaningful.

\section{Gas-liquid mass transfer evaluation}

In order to find out the reason for the enhancement effect by MNS, the $\mathrm{H}_{2}$ gas-liquid mass transfer was evaluated based on the dissolved $\mathrm{H}_{2}$ concentration. Gas mass transfer in the two reactors occurs in two zones. Gas transfer in the headspace happens through a very thin liquid boundary layer between the bulk gas and the culture cells. The mass transfer in the liquid phase is characterized through quantification of the volumetric coefficient $\left(k_{\mathrm{L}} a\right)$. Vega et al. ${ }^{43}$ have described the multiple steps when mass transfer occurs from gas to liquid phases, which involve (1) the absorption of a gaseous substrate across the gasliquid interface, (2) the transfer of the dissolved gas to the fermentation media, and (3) diffusion through the culture media to the cell surface. And the most sparingly soluble gases utilized in the biochemical reactions trigger the major resistance in the liquid film around the gas-liquid interface. ${ }^{\mathbf{4 4 , 4 5}}$ 

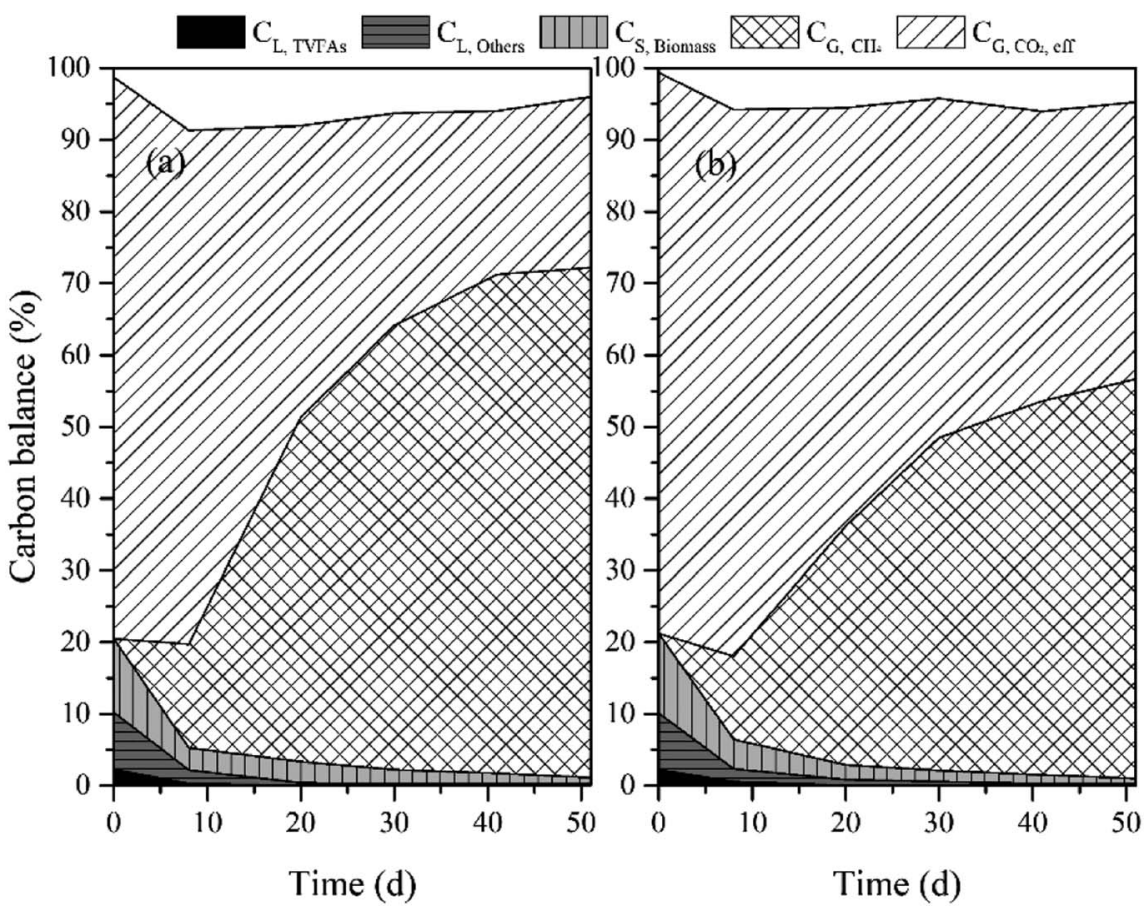

Fig. 6 Carbon balance analysis for MNSR (a) and CMSR (b).

Table 1 Energy consumption for the two reactor systems

\begin{tabular}{lllll}
\hline Reactor & $E_{\text {pump }}(\mathrm{W})$ & $E_{\text {stirrer }}(\mathrm{W})$ & $E_{\text {consumed }}(\mathrm{W})$ & $R\left(\mathrm{~L} \mathrm{~kW}^{-1}\right)$ \\
\hline MNSR & $2.80 \times 10^{4}$ & $1.59 \times 10^{4}$ & $4.39 \times 10^{4}$ & 1.80 \\
CMSR & $2.69 \times 10^{4}$ & $1.39 \times 10^{4}$ & $4.08 \times 10^{4}$ & 1.45 \\
\hline
\end{tabular}

Because during the batch bioconversion experiments, the $k_{\mathrm{L}} a$ value was continuously varying, the $k_{\mathrm{L}} a$ in this study was evaluated before incubation by analyzing the dissolved $\mathrm{H}_{2}$ concentration in the liquid. As shown in Fig. 7, the $k_{\mathrm{L}} a$ value in the MNSR $\left(12.95 \mathrm{~h}^{-1}\right)$ is almost twice that in the $\operatorname{CMSR}\left(6.6 \mathrm{~h}^{-1}\right)$, most probably due to the increase in specific surface area because of much smaller bubble size.

The specific surface area to liquid volume ratio was calculated by according to both the micro-scale and nano-scale bubble size distribution in the two reactors (Fig. S3†). The average bubble size in the CMSR and MNSR was determined as about $845 \mu \mathrm{m}$ and $220 \mu \mathrm{m}$, respectively, corresponding to the total surface area to liquid volume of $5640 \mathrm{~cm}^{2} / \mathrm{L}_{\mathrm{R}}$, and 48042 $\mathrm{cm}^{2} / \mathrm{L}_{\mathrm{R}}$. This specific surface area has been increased by one order of magnitude, implying more sufficient contact chance between methanogens and the gaseous substrates.

Results show the significant difference in the $k_{\mathrm{L}} a$ value of MNSR and CMSR. There are several parameters, which have an influence on the $k_{\mathrm{L}} a$ in a reactor. Rittman et al. ${ }^{16}$ (2015) demonstrated that at a given reactor configuration, agitation, stirrer types, gas flow rate, gas-limitation fundamentals and the sparger type are the most relevant. The $k_{\mathrm{L}} a-\mathrm{H}_{2}$ in different studies were summarized in Table 2 . Nielsen et al. ${ }^{\mathbf{4 6}}$ proposed that CSTR was the most used reactor configuration for bioconversion of $\mathrm{H}_{2}$ and $\mathrm{CO}_{2}$ to $\mathrm{CH}_{4}$ by 2011, due to the effective gas-liquid mass transfer in the CSTR. In the study of Bassani et $a l .{ }^{26}$ the effect of sparger type on $k_{\mathrm{L}} a$ value was not very significant, but gas recirculation rate affected the bioconversion significantly. While, in this study, the sparger type is still an important factor. The smaller pore size lead to the higher $k_{\mathrm{L}} a$ value with the assistance by magnetic stirrers to provide sufficient mixing. However, the $k_{\mathrm{L}} a$ obtained from this study is much lower than that from Bassani et al. ${ }^{26}$ possibly resulted from the lower recirculation rate applied in this study (40 $\mathrm{mL} \min ^{-1}$ ). Therefore, the subsequent experiments will be carried out to optimize the $k_{\mathrm{L}} a$ value taking higher recirculation

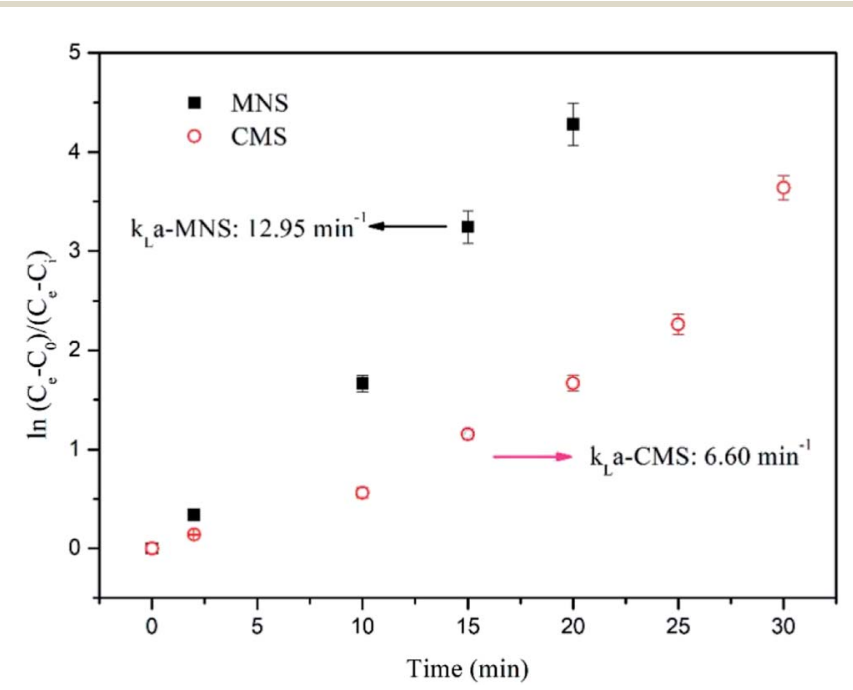

Fig. 7 Determination of $k_{\llcorner} a-\mathrm{H}_{2}$ from dissolved $\mathrm{H}_{2}$ concentration data. Solid squares denote MNSR and open circles denote CMSR. 
rate and higher temperature into consideration. In a summary, these results demonstrate that $k_{\mathrm{L}} a$ is a key factor for the enhanced $\mathrm{CH}_{4}$ production from the MNSR.

\section{Conclusions}

The enhanced bioconversion of $\mathrm{H}_{2}$ and $\mathrm{CO}_{2}$ to $\mathrm{CH}_{4}$ was realized by using the MNS. The maximum MER of $171.4 \mathrm{mmol} / \mathrm{L}_{\mathrm{R}} / \mathrm{d}$ in the MNSR is much higher than that in the CMSR $(136.1 \mathrm{mmol} /$ $\mathrm{L}_{\mathrm{R}} / \mathrm{d}$ ). The MNSR also displayed superior biomass growth with specific growth rate of $0.15 \mathrm{~d}^{-1}$ than that of CMSR. The VFAs accumulation was not detectable in MNSR. Higher gas-liquid mass transfer was achieved in the MNSR than that in the CMSR. A higher energy-product ratio and economic analysis indicates that MNS has applicable potential for improvement of $\mathrm{CO}_{2}$ and $\mathrm{H}_{2}$ conversion into $\mathrm{CH}_{4}$ in large-scale plants.

\section{Conflicts of interest}

There are no conflicts to declare.

\section{Acknowledgements}

This work was financially supported by JFE steel cooperation. The first author acknowledges the support of the China Scholarship Council (No. 201506400049).

\section{References}

1 G. J. Francisco, A. Chakama and X. Feng, Sep. Purif. Technol., 2010, 75, 205-213.

2 Greenhouse Gas Inventory Office of Japan (GIO), 2017, ch. 2, pp. 3-6.

3 U. E. Aronu, H. F. Svendsen and K. A. Hoff, Int. J. Greenhouse Gas Control, 2010, 4, 771-775.

4 A. Sayari, Y. Belmabkhout and R. Serna-Guerrero, Chem. Eng. J., 2010, 171, 760-774.

5 G. Xu, F. Liang, Y. Yang, Y. Hu, K. Zhang and W. Liu, Energies, 2014, 7, 3484-3502.

6 Y. Zee, L. C. Thiam, W. Z. Peng, R. M. Abdul and S. Chai, J. Porous Mater., 2013, 20, 1457-1475.

7 B. Pau, P. Sebastia, G. Rafael, D. Maria and C. Jesus, J. Chem. Technol. Biotechnol., 2016, 91, 921-927.

8 M. C. A. A. van Eerten-Jansen, N. C. Jansen, C. M. Plugge, V. Wilde, C. J. N. Buisman and A. T. Heijne, J. Chem. Technol. Biotechnol., 2015, 90, 963-970.

9 M. Burkhardt and G. Busch, Appl. Energy, 2013, 111, 74-79.

10 M. K. Lam, K. T. Lee and A. R. Mohamed, Int. J. Greenhouse Gas Control, 2012, 10, 456-469.

11 H. S. Jee, N. Nishio and S. Nagai, J. Ferment. Technol., 1988, 66, 235-238.

12 D. Ju, J. Shin, H. Lee and S. Kong, Desalination, 2008, 234, 409-415.

13 M. Szuhaj, N. Acs, R. Tengolics, A. Bodor, G. Rakhely and K. L. Kovacs, Biotechnol. Biofuels, 2016, 9, 102.

14 S. K. Hoekman, A. Broch, C. Robbins and R. Purcell, Int. J. Greenhouse Gas Control, 2010, 4, 44-50. 
15 M. D. Redwood, R. L. Orozco, A. J. Majewski and L. E. Macaskie, Bioresour. Technol., 2012, 107, 166-174.

16 S. Rittmann, A. Seifert and C. Herwig, Crit. Rev. Biotechnol., 2015, 35, 141-151.

17 N. Nishimura, S. Kitaura, A. Mimura and Y. Takahara, J. Ferment. Bioeng., 1991, 72, 280-284.

18 I. Bassani, P. G. Kougias, L. Treu and I. Angelidaki, Environ. Sci. Technol., 2015, 49, 12585-12593.

19 I. Bassani, P. G. Kougias and I. Angelidaki, Bioresour. Technol., 2016, 221, 485-491.

20 I. Diaz, C. Perez, N. Alfaro and F. Fdz-Polanco, Bioresour. Technol., 2015, 185, 246-253.

21 D. Cheng, J. Cheng, X. Li, X. Wang, C. Yang and Z. Mao, Chem. Eng. Sci., 2012, 75, 256-266.

22 S. R. Guiot, R. Cimpoia and G. Carayon, Environ. Sci. Technol., 2011, 45, 2006-2012.

23 G. Luo and I. Angelidaki, Appl. Microbiol. Biotechnol., 2013, 97, 1373-1381.

24 S. Zhang, D. Wang, F. Bu, X. Zhang and P. Fan, Surf. Interface Anal., 2013, 45, 1152-1157.

25 P. G. Kougias, L. Treu, D. P. Benavente, K. Boe, S. Campanaro and I. Angelidaki, Bioresour. Technol., 2017, 225, 429-437.

26 I. Bassani, P. G. Kougias, L. Treu, H. Porte, S. Campanaro and I. Angelidaki, Bioresour. Technol., 2017, 234, 310-319.

27 A. J. Dixon, A. H. Dhanaliwala, J. L. Chen and J. A. Hossack, Ultrasound Med. Biol., 2013, 39, 1267-1276.

28 F. Kobayashi, H. Ikeura, M. Tamaki and Y. Hayata, Southeast Asia Symposium on Quality and Safety of Fresh and Fresh-cut Produce, 2010, 875, pp. 417-424.

29 K. Kugino, S. Tamaru, Y. Hisatomi and T. Sakaguchi, PLoS One, 2016, 11, 1-9.

30 A. Agarwal, W. J. Ng and Y. Liu, Chemosphere, 2011, 84, 11751180.
31 F. Ushikubo, T. Furukawa, R. Nakagawa, M. Enari, Y. Makino, Y. Kawagoe, T. Shiina and S. Oshita, Colloids Surf., A, 2010, 361, 31-37.

32 Z. Zhang and T. Maekawa, Biomass Bioenergy, 1993, 4, 439446.

33 APHA, American Public Health Association/American Water Work Association/Water Environment Federation, Washington, DC, 21st edn, 2005.

34 W. Huang, W. Huang, T. Yuan, Z. Zhao, W. Cai, Z. Zhang, Z. Lei and C. Feng, Water Res., 2016, 90, 344-353.

35 P. Tsapekos, P. G. Kougias, L. Treu, S. Campanaro and I. Angelidaki, Appl. Energy, 2016, 185, 126-135.

36 P. J. Weimer and J. G. Zeikus, Arch. Microbiol., 1978, 119, 4957.

37 P. H. Roennow and L. A. H. Gunnarsson, FEMS Microbiol. Lett., 1982, 14, 311-315.

38 J. Lee, J. Kim, W. Chang and D. Pak, J. Chem. Technol. Biotechnol., 2012, 87, 844-847.

39 P. C. Munasinghe and S. K. Khanal, RSC Adv., 2014, 4, 3757537581.

40 D. Karakashev, D. J. Batstone, E. Trably and I. Angelidaki, Appl. Environ. Microbiol., 2006, 72, 5138-5141.

41 M. J. Lee and S. H. Zinder, Appl. Environ. Microbiol., 1988, 54, 1457-1461.

42 R. Cord-Ruwisch, D. R. Lovley and B. Schink, Appl. Environ. Microbiol., 1998, 64, 2232-2236.

43 J. L. Vega, E. C. Clausen and J. L. Gaddy, Biotechnol. Bioeng., 1989, 34, 774-784.

44 K. T. Klasson, C. M. D. Ackerson, E. C. Clausen and J. L. Gaddy, Int. J. Hydrogen Energy, 1992, 17, 281-288.

45 P. C. Munasinghe and S. K. Khanal, Biotechnol. Prog., 2010, 26, 1616-1621.

46 J. Nielsen, J. Villadsen, and G. Liden, Bioreaction engineering principles, Springer, New York, 2011, ch. 9, pp. 383-458. 